Check for updates

Cite this: J. Mater. Chem. C, 2020 8, 16443

Received 13th August 2020,

Accepted 15th October 2020

DOI: $10.1039 / \mathrm{d} 0 \mathrm{tc} 03864 \mathrm{~d}$

rsc.li/materials-c

\section{One-pot synthesis of a stable and cost-effective silver particle-free ink for inkjet-printed flexible electronics $\dagger$}

\author{
Wendong Yang, (D)*a Florian Mathies, (D) ${ }^{a}$ Eva L. Unger, (D) ${ }^{a}$ Felix Hermerschmidt (D) ${ }^{b}$ \\ and Emil J. W. List-Kratochvil (D) ab
}

\begin{abstract}
Silver particle-free inks display immense superiority and potential over silver nanoparticle-based inks in the aspect of synthesis, flexibility and low-temperature processing, which has attracted considerable research interest as an alternative for fabricating conductive structures in recent years. Although recent research on silver particle-free inks has led to beneficial results, there are still some drawbacks: some of the inks are chemically unstable and hence are not suitable for industrial inkjet printing process, although they have good conductivity; while others are cheap in terms of raw material costs but are complicated to make due to the complex synthetic route or using hazardous procedures, or are not compatible with inkjet printing. Therefore, it will be advantageous to develop a stable, cheap and inkjetprintable silver-particle free ink using a simple synthetic procedure. Alcohols are favorable solvents for silver particle-free inks that can provide the ink with essential fluid properties for inkjet printing. However, they have some negative effects on the ink performance due to their physicochemical properties, which should be avoided. In this work, a simple do-it-yourself silver particle-free ink is presented, which shows high chemical stability, low cost and good printability. The ink is formulated via a simple silver oxalate precursor route in alcohols. The fluid property, thermal property, stability and electrical performance of the inks based on different alcohols were investigated and optimized to obtain the final ink for printing on glass and flexible polyimide substrates. The printed Ag features yielded a resistivity of $15.46 \mu \Omega \mathrm{cm}$ at a sintering temperature of $180{ }^{\circ} \mathrm{C}$, which is equivalent to 10 times resistivity of bulk silver. Based on a comprehensive assessment, we can offer a low-cost, easy-to-make, reliable and highly competitive ink for flexible printed electronics.
\end{abstract}

\section{Introduction}

Printed flexible electronics is one of the fastest-growing technologies in the world, which is of great significance to industries as diverse as healthcare, electronics, consumer goods and mobility. This technology is a direct additive deposition process to print the ink material onto various flexible substrates, which greatly simplifies the fabrication process of electronic devices. Besides, it offers a number of attractive new virtues to electronic products such as being wearable, flexible, bendable, more lightweight and even transparent. ${ }^{1,2}$ It is improving existing electronics by creating products with new features or replacing existing components with

\footnotetext{
${ }^{a}$ Helmholtz-Zentrum Berlin für Materialien und Energie GmbH, Forschergruppe Generative Fertigungsprozesse, Hahn-Meitner-Platz 1, 14109 Berlin, Germany. E-mail: emil.list-kratochvil@helmholtz-berlin.de, wendong.yang@helmholtz-berlin.de

${ }^{b}$ Humboldt-Universität zu Berlin, Institut für Physik, Institut für Chemie, IRIS Adlershof, Brook-Taylor-Straße 6, 12489 Berlin, Germany.E-mail: emil.list-kratochvil@hu-berlin.de

$\dagger$ Electronic supplementary information (ESI) available. See DOI: 10.1039/d0tc03864d
}

higher performance alternatives in a simpler, faster, more costeffective and eco-friendly way.

Conductive inks play a central role for printed flexible electronics since they find application in a wide range of newly-emerged electronic and energy devices. ${ }^{3,4}$ Currently, a number of inks based on silver, ${ }^{5-9}$ copper, ${ }^{10-16}$ graphene, ${ }^{17-21}$ carbon $^{22,23}$ and conductive polymers, ${ }^{24-26}$ have been explored for printed flexible electronics. Among them, silver-based inks have been the favored metal inks because they are more costeffective than Au-based metal inks, more stable than Cu-based on inks and have better conductivity than polymer or carbonbased inks. Different kinds of silver inks such as silver nanoparticle inks, ${ }^{27-30}$ silver nanowire inks ${ }^{31-36}$ and silver particle-free inks $^{37-40}$ have already been devoloped for inkjet printing of conductive structures. Silver particle-free ink, composed of silver precursor, complexing agent/ligand and volatile solvents, displays immense superiority and potential in the aspect of flexibility and low-temperature processing over silver nano inks. ${ }^{41}$ This type of ink exists in a solution form so that problems 
such as nozzle clogging occurred in the printing process are avoided. In this regard, features with fine resolutions can be printed. ${ }^{42}$ After post-treatment, desired conductivity can be achieved on a wide range of flexible substrates.

Up to now, although much research on silver particle-free inks has been performed, there are still some drawbacks: (1) in some cases, the obtained ink is less stable and decomposes to silver particles over time such as silver carbonate $i n k^{40}$ and silver oxide ink. ${ }^{43}$ This is mostly due to the utilization of volatile solvents and ligands with weak reducibility. In other cases, the obtained ink has a lower sintering temperature in the range of 70-90 ${ }^{\circ}$ C. ${ }^{9,44,45}$ These inks may not be suitable for a long-term inkjet printing process because it may lead to the formation of silver particles in the nozzle and clog it due to the quick decomposition of the ink. ${ }^{46}$ Also, due to the fast evaporation of the components in ink, the quality of silver films is usually decreased; (2) some of the synthetic methods of these inks are not economically feasible and not easy to make because of cost and safety concerns. For instance, the silver precursors for $\beta$-diketonate silver particle-free ink ${ }^{47}$ and silver(I) 2-[2-(2-methoxyethoxy)ethoxy]acetate $i^{37}$ are required a complex and timeconsuming process to synthesize, and the precursor for silver hexafluoroacetylacetonate cyclooctadiene ink are expensive and need to be formulated in glove box due to the usage of toxic toluene. ${ }^{48}$ For silver acetate-based particle-free inks, formic acid and ethylamine are usually adopted. ${ }^{46,49}$ Both chemicals are not safe, especially the latter which has higher toxicity. Besides, a 12-aging time is required for such inks to avoid any particle formation when using the ink. Although some of the developed silver particle-free inks are cheap in terms of material cost, they are not easy to print due to the stability issue and unmatched fluid parameters required by a specific printer. (3) The influences of changes in fluid parameters on the printability of the formulated ink and the performance of the resultant film are rarely examined. Therefore, we see a certain need to develop a stable, low-cost and printable silver-particle free ink using nontoxic solvents and simple synthetic procedure.

Solvents make up the majority of the silver particle-free ink. They have two functions; one is to increase the solubility of the silver precursor and the other is to provide the ink with essential fluid properties for printing. Selection of appropriate solvents, therefore, is important to the ink formulation. Alcohols with low boiling point and low molecular weight are by far the most popular choice since they have lower toxicity and less organic residues after post-treatment. Besides, some alcohols are reductive, which is conducive to the film formation. ${ }^{40}$ However, alcohols also have negative effects when using as the ink solvents.

Two phenomena often occur during the sintering/annealing/ drying of alcohol-based inks, the solvent shrinkage effect (Marangoni effect) $^{50}$ and the coffee ring effect. ${ }^{51-53}$ The former will result in a film with a structure that has a thin edge and thick center, while the latter will produce a film that has a thick edge, thin center, or even no particulate at the center. Both phenomena seriously affect the electrical and mechanical performance of the sintered films or patterns, limiting the wide device applications of the inks. However, the two effects coexist and which one dominates depends on the physical properties of the solvent. Some solvents are dominated by the shrinkage effect such as water. ${ }^{54}$ Some are dominated by coffee ring effect such as ethanol, and for some solvents, the two phenomena are not obvious.

On the other hand, in order to achieve good printing on specific substrates, the ink should have certain fluid properties. These properties are also determined by the type of solvents selected. However, some alcohols, such as methanol, ethanol and isopropanol, have very low viscosity and contact angle, which spread rapidly on the glass and polymer substrates. Therefore, control of spreading is an issue to be solved. Besides, the volatility of these alcohols can cause printing issues such as causing the crystal precipitation in ink and clog the printhead. ${ }^{55}$ Moreover, these alcohols are prone to resulting in a non-uniform surface structure on the substrate after post-treatment, which should also be avoided. Therefore, it is necessary to study the solvent effects of the silver particle-free inks before formulating an ink that can be printed.

Currently, most research towards silver particle-free inks mainly concentrated on the enhancement of conductivity and adhesion of the resultant metal silver films, the decomposition mechanism of the metal-ligand complex and the effects of the ligand's type on the ink properties and the morphology of the associated films. As for solvent effects on silver particle-free ink, to our knowledge, no research reports.

In this work, a stable, transparent and printable silver particlefree ink was developed using a facile alcohol-based synthesis route. The fluid property, thermal property, stability and electrical performance of the inks based on different alcohols were investigated and characterized, where mixed alcohols with a proper ratio were chosen to obtain the final ink for printing. Conductive silver patterns with a flat surface and compact structure as well as high resolutions were printed on both flexible polymer and glass substrates successfully using industrial scale printerheads. Additionally, we assessed the cost and performance of our ink.

\section{Experimental section}

\subsection{Preparation of silver ink and film}

Silver nitrate $\left(\mathrm{AgNO}_{3}\right)$, oxalic acid $\left(\mathrm{H}_{2} \mathrm{C}_{2} \mathrm{O}_{4}\right)$, sodium hydroxide $(\mathrm{NaOH}), 1,2$-diaminopropane $\left(\mathrm{C}_{3} \mathrm{H}_{10} \mathrm{~N}_{2}, 1,2\right.$-DAP $)$, ethanol $\left(\mathrm{C}_{2} \mathrm{H}_{6} \mathrm{O}\right.$, EA), 2-methoxyethanol $\left(\mathrm{C}_{3} \mathrm{H}_{8} \mathrm{O}_{2}, 2\right.$-MEA), butanol $\left(\mathrm{C}_{4} \mathrm{H}_{10} \mathrm{O}, \mathrm{BA}\right)$ and hexanol $\left(\mathrm{C}_{6} \mathrm{H}_{14} \mathrm{O}, \mathrm{HA}\right)$ were purchased from Sigma-Aldrich. Methanol $\left(\mathrm{CH}_{4} \mathrm{O}, \mathrm{MA}\right), 2$-propanol $\left(\mathrm{C}_{3} \mathrm{H}_{8} \mathrm{O}\right.$, IPA) and ethylene glycol $\left(\mathrm{C}_{2} \mathrm{O}_{2} \mathrm{H}_{6}, \mathrm{EG}\right)$ were purchased from Honeywell and Roth respectively. All chemicals were used without further purification. Polyimide films (PI, $127 \mu \mathrm{m}$ thick, obtained from DuPont) and glass were used as substrates. Before application, $15 \mathrm{~mm} \times$ $15 \mathrm{~mm}$ of PI films and $25 \mathrm{~mm} \times 25 \mathrm{~mm}$ of glass sheets were cleaned using deionized water and ethanol respectively and then dried.

The silver particle-free inks used in this study were prepared in alcohols using silver oxalate and 1,2-diaminopropane. The silver oxalate was prepared using the method described in our previous work. ${ }^{7}$ For ink preparation, $0.152 \mathrm{~g}$ of silver oxalate 
powder was first dispersed in $0.75 \mathrm{ml}$ of alcohol and stirred for 5 minutes. Then, $0.172 \mathrm{ml}$ of 1,2-diaminopropane amines was added. The mixture was stirred for 60 minutes to form the ink. To make a reasonable comparison, the weight of silver oxalate (0.152 g) was the same in each ink and the Ag/amine molar ratios were kept at a constant value of $1: 2$. The silver content in the ink was about $10 \mathrm{wt} \%$. Here, we tried to load more silver in the ink but it has a solubility issue. This is because the silver oxalate is sparingly soluble in alcohol and needs amine to increase its solubility by forming a soluble silver-amine complex. If we want to increase the silver content in the ink, we also need to use more amines and solvents to ensure the solubility and printability.

The silver films or silver patterns on glass and PI substrates were obtained separately by spin coating (1000 rpm, $30 \mathrm{~s})$ and drop-casting with a subsequent sintering process at selected temperatures for up to 60 minutes. Printing of the ink was conducted using a PixDro LP50 inkjet printer (SÜSS MicroTec) equipped with industrial-scale Fujifilm Dimatix Spectra SE128 piezoelectric printheads. The drops were generated by a single bias pulse with a voltage of $100 \mathrm{~V}$ and a pulse width of $10 \mu \mathrm{s}$. The jetting frequency was set to $1 \mathrm{kHz}$. Different resolutions in the range of $300 \mathrm{dpi}$ to $1050 \mathrm{dpi}$ were adopted to print the square films. The patterns and lines with different widths were printed in $750 \mathrm{dpi}$. Before printing, the ink was filtered with a PTFE filter $(0.45 \mu \mathrm{m})$.

\subsection{Characterization}

The UV/vis absorption spectra were obtained on a Lambda 950 UV-vis spectrophotometer. DI water was used as the solvent. The surface tension and contact angle of each ink on the PI substrate were measured using a drop-shape analyzer (Krüss DSA100, Germany). The viscosity of inks was measured by using a Haake rotational viscometer. X-ray diffraction (XRD) analysis was conducted on a Bruker D8 Advance X-ray diffractometer with a $\mathrm{Cu} \mathrm{K} \alpha 1$ radiation $(\lambda=0.15406 \mathrm{~nm})$. The diffraction patterns were collected at $25{ }^{\circ} \mathrm{C}$ and over a range of $20^{\circ}$ to $90^{\circ}$. The thermal behaviors of the inks were investigated with a differential scanning calorimeter (Netzsch DSC 204 F1) and a thermogravimetric analyzer (Netzsch TG 209 F1) at a heating rate of $10{ }^{\circ} \mathrm{C} \mathrm{min}^{-1}$ under an argon atmosphere and a nitrogen atmosphere, respectively. Aluminum pans with pierced lids were used to load the inks. The gas outlet of the thermogravimetric analyzer was directly coupled with a mass spectrometer (Netzsch QMS 403C) to monitor the gaseous products evolved during heating. The surface morphologies and chemical composition of the obtained silver films were observed via a scanning electron microscope (HITACHI S-4100) and a surface energy disperse spectrometer (EDX). The sheet resistivity was measured using a 4 point probe system (Jandel Engineering). The average thickness of the film was measured by SEM to calculate its resistivity.

\section{Results and discussion}

\subsection{Ink design, synthesis and characterization}

The properties of the silver particle-free ink vary primarily with the type of silver precursor, the ligand and the solvent used to solubilize them. The key point in formulating an ideal ink, therefore, lies in the careful selection of these components.

Silver oxalate was chosen as the core of our ink because it has a high silver content (71 wt\%), a simple synthetic process and easily decomposes to silver without leaving organic residues. 1,2Diaminopropane, a bi-dentate aliphatic amine with a boiling point of $119{ }^{\circ} \mathrm{C}$ was used as the ligand for silver oxalate. Five types of alcohols with small molecular weight were selected as the ink solvents respectively because they are less toxic and easily available.

Silver particle-free inks were prepared by simply dissolving the synthesized white silver oxalate powder into the different alcohols using 1,2-diaminopropane (1,2-DAP) as the ligand (Fig. 1a). The silver oxalate was produced through the reaction of sodium oxalate and silver nitrate directly. As expected, sparingly soluble silver oxalate powder gradually dissolved in each alcohol containing 1,2-DAP, mainly via the complexing process proposed in Fig. 1b, resulting in a transparent ink. Compared to the synthetic methods of inks based on $\beta$-diketonate silver ${ }^{47}$ or silver(I) 2-[2-(2-methoxyethoxy)ethoxy] acetate $^{37}$ or silver hexafluoroacetylacetonate cyclooctadiene, ${ }^{48}$ our one-pot approach is easy to handle and the process is facile, quick and cost-effective. In comparison with inks based on silver acetate, ${ }^{46,49}$ we don't require an overnight aging time of 12 hours to let the produced particle settle and the utilization of pungent formic acid and toxic ethylamine are avoided, which is relatively safe. In other words, a facile synthesis route was developed by simply mixing the selected chemicals together to make your own silver particlefree conductive ink.

Here, it should be noted that the dissolution rate of silver oxalate powder varies with the selected alcohols containing 1,2DAP. The powder dissolved within 5 minutes in methanol (MA), 2-methoxyethanol (2-ME) and ethylene glycol (EG) inks. However, in the solvent of ethanol and 2-propanol, the dissolvable rate was slow and more time was necessary, especially for the 2-propanol. The dissolution behavior of the silver oxalate powder in butanol and hexanol containing 1,2-DAP was also observed. Both inks showed slow dissolution rate and precipitation occurs over time (see Fig. S1 in ESI $\dagger$ ).

To realize the printing on specific substrates, the ink should have certain fluid properties compatible with the utilized printhead. ${ }^{56}$ These properties relate to viscosity, surface tension, evaporation rate and wettability with the substrate, which are

(a)
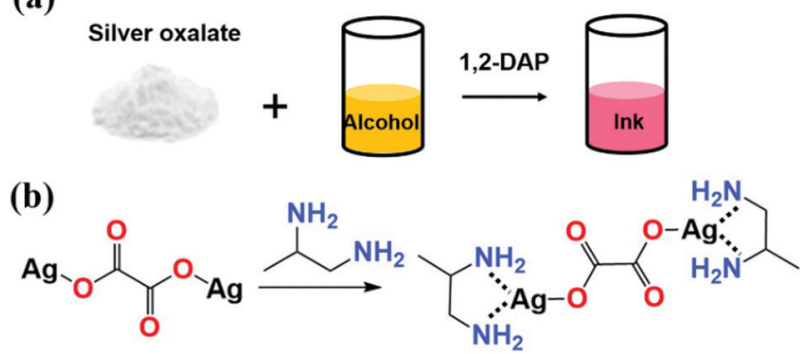

Fig. 1 (a) A one-pot procedure for the formulation of silver particle-free ink and (b) proposed chemical reaction involved in the formulation of ink. 
Table 1 Fluid properties of the silver oxalate inks prepared using different alcohol solvents

\begin{tabular}{|c|c|c|c|c|c|}
\hline Fluid parameters & $\begin{array}{l}\text { Methanol (MA) } \\
\text { ink }\end{array}$ & $\begin{array}{l}\text { Ethanol (EA) } \\
\text { ink }\end{array}$ & 2-Propanol (IPA) ink & $\begin{array}{l}\text { 2-Methoxyethanol } \\
\text { (2-MEA) ink }\end{array}$ & $\begin{array}{l}\text { Ethylene } \\
\text { glycol (EG) ink }\end{array}$ \\
\hline Surface tension $\left(\gamma, \mathrm{mN} \mathrm{m}^{-1}\right)$ & 24.63 & 23.07 & 19.00 & 33.11 & 47.88 \\
\hline Density $\left(\rho, \mathrm{g} \mathrm{cm}^{-3}\right)$ & 0.94 & 0.93 & 0.83 & 1.1 & 1.2 \\
\hline Contact angle (PI substrate) & $15.72^{\circ}$ & $23.35^{\circ}$ & $31.09^{\circ}$ & $24.03^{\circ}$ & $40.33^{\circ}$ \\
\hline$Z$ value & 37.55 & 23.01 & 10.46 & 20.75 & 3.29 \\
\hline
\end{tabular}

determined by the solvents used. Considering this, the fluid parameters of the five silver inks were investigated to check the printability of each ink; the results are listed in Table 1 . The surface tension and contact angle images are given in Fig. S2 in ESI. $\dagger$

As seen, the ink from ethylene glycol has higher surface tension and viscosity in the five types of inks, with a value of $47.88 \mathrm{mN} \mathrm{m}^{-1}$ and $16.62 \mathrm{mPa}$ s, respectively. On the contrary, the ink from methanol has a lower value, especially in the viscosity $(0.758 \mathrm{mPa}$ s). For printing, an ink with high surface tension helps to suppress the formation of satellite droplets and increase the printing velocity, thereby resulting in a good print quality. ${ }^{57}$ The typical values for industrial printheads are in the range of $25-35 \mathrm{mN} \mathrm{m}^{-1}$. As for viscosity, a low value is easier to print with an inkjet head. However, it should be compatible with the printhead. For piezoelectric printheads, the value should be in the range of $8-15 \mathrm{mPa}$ s. From Table 1, it can be seen that the viscosity values of the five inks are all out of this range.

In terms of volatility, ethylene glycol has a high boiling point of $197.6{ }^{\circ} \mathrm{C}$, followed by 2-ME. The remaining three are all volatile, which might lead to nozzle clogging which is one of the most common failure modes of drop-on-demand inkjet printers. In the aspect of wettability, the methanol ink spreads strongly on the PI substrate and a contact angle of $15.72^{\circ}$ is measured. For printing fine features on hydrophobic substrates such as glass or polymer films, a large contact angle may be beneficial to achieve patterns with high resolutions. Especially ethylene glycol ink has a relatively large contact angle of $40.33^{\circ}$, which would contribute to the well-defined printed structures and reliable adhesion on the substrate.

The dimensionless number $Z$, the inverse of the Ohnesorge number, is often used to predict whether a liquid can be printed. It is defined as the ratio between the Reynolds number and a square root of the Weber number, as shown below,

$$
Z=\frac{N_{\mathrm{Re}}}{\left(N_{\mathrm{we}}\right)^{1 / 2}}=\frac{(\alpha \rho \gamma)^{1 / 2}}{\eta}
$$

where $\gamma, \rho$ and $\eta$ are the surface tension, the density and the viscosity of the liquid, respectively, and $\alpha$ is the diameter of the nozzle (in our case $35 \mu \mathrm{m}$ ). According to Jang et al., the liquid with a $Z$ value in the range from 4 to 14 can be used for inkjet printing. ${ }^{58}$ Based on the measured fluid parameters, the $Z$ values of the five inks were calculated and listed in Table 1 . Only the ink from IPA may be suitable for printing.

Apart from the fluid properties, we also investigated the stability, thermal property, and electrical performance of the asprepared five silver inks, see Section S1 in ESI, $†$ from Fig. S3-S7
(ESI $\dagger$ ). The results show that the solvent type has little effect on the thermal behaviour of the ink but mainly affects the morphology and electrical performance of the associated films. Each ink has its advantages and disadvantages either in the fluid properties or in the stability and electrical performance. To get a balance between these properties, we targeted a mixture of solvents as the ideal choice for an optimal ink, which can not only provide the essential fluid properties for the inkjet printing but also can result in highly conductive films with good quality at low temperature.

\subsection{Film structure from inks based on mixed alcohol solvents}

In Section 3.1, we investigated the structural and electrical properties of the films produced from the five silver inks (see ESI, $\dagger$ Fig. S5 and S6). Together with the stability and the fluid properties of each ink, we found that the ink from methanol (MA) has better stability and uniform surface structure as well as lower resistivity but shows the obvious coffee-ring effect and non-ideal fluid properties such as fast evaporation rate and stronger wetting behavior; the ink from ethylene glycol (EG) has a structure consisting of big silver crystals and good fluid properties for print quality but the film has a higher resistivity. After consideration, a mixture of these two solvents was selected as the ink solvent. Inks with different MA/EG ratios that are varied from $0: 5$ to $5: 0$ were formulated and characterized.

In terms of fluid properties, the inks in $4: 1$ and $3: 2$ spread easily on the glass substrates, showing good wettability and flowability. The sintered films from these two inks are slightly yellow, and the film from the ink in $4: 1$ shows a coffee-ring effect. For the inks in $1: 4$ and $2: 3$, they flow and evaporate slowly, and cannot cover the whole glass after sintering at $150{ }^{\circ} \mathrm{C}$, and the resultant films are dark yellow. With a mixed solvent in a proper MA/EG ratio, the fluid properties required by a printer and the film morphology could be guaranteed.

$\mathrm{XRD}, \mathrm{SEM}$ and four-probe analyses were employed to investigate the physical phase, morphology and resistivity of the resultant films to determine the optimal mixing ratio; the results are given in Fig. 2. Clearly, the X-ray diffraction patterns of all the films exhibit a crystalline silver structure (JCPDS card no. 04-0783, Fig. 2a), indicating that the silver-amine complex in each ink has been transformed into metallic silver. Small peaks relative to the PI substrates were also observed, which indicates that the films are thin. As the MA concentration increases, the intensity of the (111) diffraction peak reaches its maximum at $3: 2$, meaning an increased crystallization of the silver particles in the film.

Fig. $2 \mathrm{~b}$ shows the corresponding surface morphology of the silver films on PI substrates (the SEM images on glass substrates 
(a)

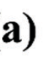

(b)
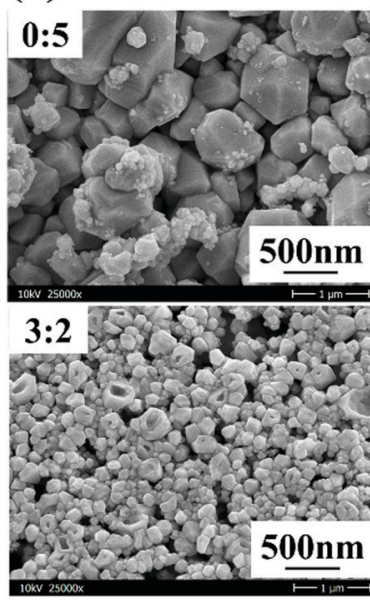

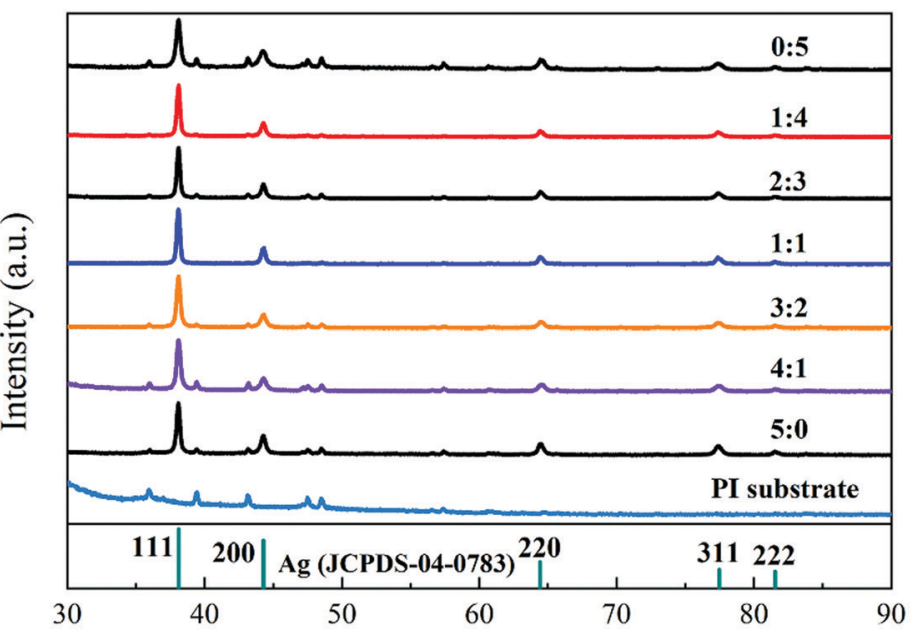

$2 \theta\left({ }^{\circ}\right)$
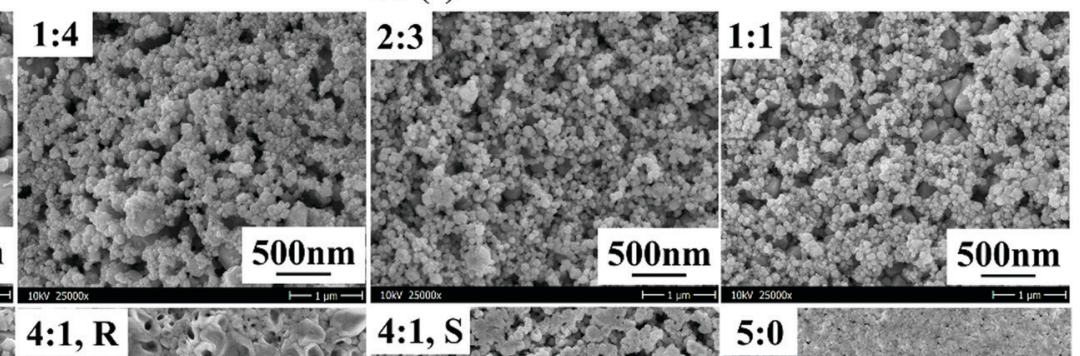

$4: 1, \mathrm{R}$

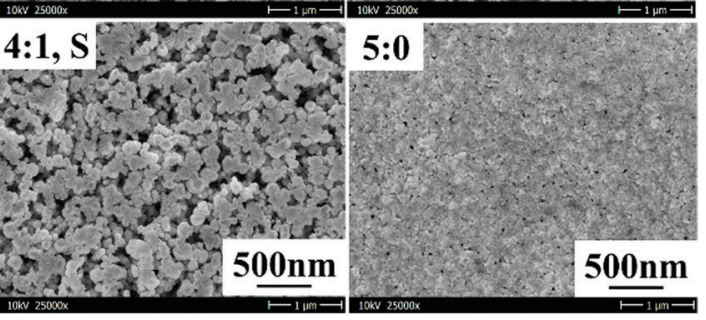

Fig. 2 (a) XRD patterns and (b) SEM images of silver films on PI substrate sintered at $150{ }^{\circ} \mathrm{C}$ for 60 min from silver oxalate inks prepared using a mixture of $M A$ and $E G$ in different ratios ( $R$ and $S$ represent the roughest and smoothest part of the film).

were given in Fig. S8a and $b$ in ESI $\dagger)$. As seen, the film quality is significantly improved with the increase of the MA concentration, with a surface change from loose to dense. The surface morphology of the film from inks with MA/EG in $1: 4,2: 3$ and $1: 1$ revealed a microstructure that was composed of silver particles with big and small sizes, where the later was covered on the top of the former. Meanwhile, these films all have varying degrees of solvent shrinkage effect in appearance and the ink in $1: 4$ is most serious. By contrast, the film from the ink in $3: 2$ and $4: 1$ presented a microstructure that was composed of hollow silver nanoparticles in a good connection. The film produced from the 4:1 ink shows an obvious coffee-ring effect in appearance with a smooth part and roughness part. These microstructure differences are associated with the physical characteristics of the MA and EG.

The resistivity data is given in Fig. 3. As the MA content increases, the resistivity of the silver film decreases drastically. This can be easily understood. When the MA/EG is $1: 4$, the MA content is small, the viscosity of the ink is large, mass transfer is hindered during the sintering, and silver ions cannot be completely reduced and the EG cannot be completely volatile, thereby making the resistivity relatively high. On the contrary, when the MA/EG is $4: 1$, the EG content is relatively small, the reduction of silver ions is complete and there are fewer organic residues left in the produced films, thereby resulting in a lower resistivity. Here, considering that the fast evaporation of MA will not be beneficial to the printing, we chose $3: 2$ as the optimal ratio to formulate the ink for the later printing.

The surface tension, the contact angle and the density of the optimal ink (MA/EG $3: 2$ ) were measured to be $31.09 \mathrm{mN} \mathrm{m}^{-1}, 27.9^{\circ}$ and $1.02 \mathrm{~g} \mathrm{~cm}^{-3}$, respectively. The viscosity is about $8-9 \mathrm{mPa}$. These values are within the range of fluid parameters required by a piezoelectric printer, indicating that the ink can be printed.

\subsection{Stability and conductivity of the optimal silver ink}

Stability is always an important concern for ink performance. For silver particle-free ink, there's a possibility that its components could react with each other over time, leading to the formation of silver particles, precipitation and phase separation, which is not good for long shelf-life and printing. This is especially true when the inks contain reductive components such as reducible alcohols or amines or formic acid. In our case, the inks with different 


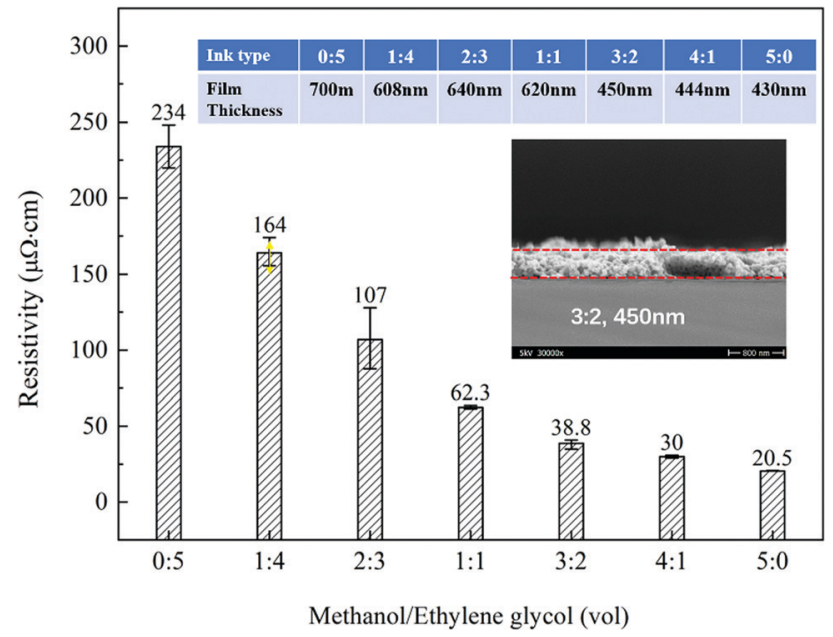

Fig. 3 Resistivity of silver films obtained at $150{ }^{\circ} \mathrm{C}$ for 60 min from silver oxalate inks prepared using a mixture of $M A$ and $E G$ in different ratios.

MA/EG ratios were found to be visually and chemically stable over time. After storing in a fridge at $5{ }^{\circ} \mathrm{C}$ for 60 days, all of them are still transparent without color change and particle precipitation (Fig. 4a), indicating good shelf life.

The electrical performance of the optimal silver ink as a function of sintering time and the temperature was studied and the results are given in Fig. $4 \mathrm{~b}$. It can be seen that the resistivity is largely independent of sintering temperature above $180{ }^{\circ} \mathrm{C}$ and the sintering time is more than 30 minutes, with a value $(15.46 \mu \Omega \mathrm{cm})$ equivalent to 10 times of bulk silver $(1.59 \mu \Omega \mathrm{cm})$. Although this value is higher than that of bulk silver, it can

(a)
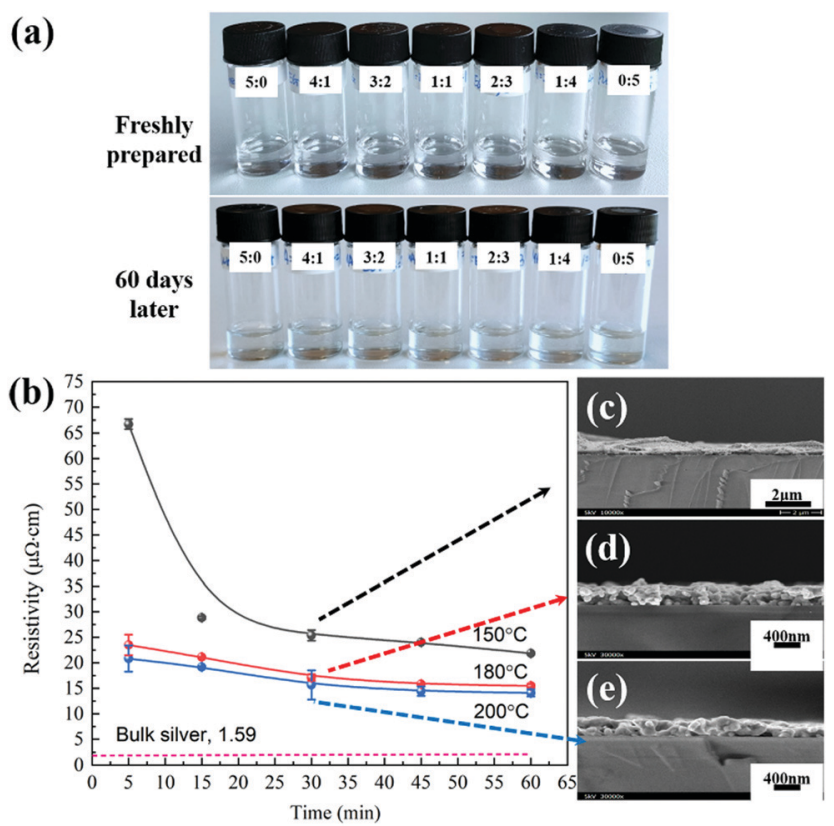

Fig. 4 (a) Photographs of the inks with different MA/EG ratios stored in a fridge at $5{ }^{\circ} \mathrm{C}$ for 60 days show no color change, (b) the resistivity of the silver film from the optimal ink as the function of sintering temperature and time, (c-e) the cross-section images of the films sintered at $150{ }^{\circ} \mathrm{C}, 180^{\circ} \mathrm{C}$ and $200{ }^{\circ} \mathrm{C}$ for 30 minutes. meet the electrical requirements of most electronic products. As for the reason, it might be associated with the low content of silver in the ink and the sintering parameters as well as the degree of organic residues from EG. We tried to sinter the ink at $100{ }^{\circ} \mathrm{C}$ for 2 to 3 hours. However, due to the inadequate evaporation and decomposition of EG $\left(\mathrm{bp}=197^{\circ} \mathrm{C}\right)$, a resistivity close to $15.46 \mu \Omega \mathrm{cm}$ cannot be achieved.

The cross-section images show that the thickness of the film decreases with the increase of the sintering temperature (Fig. 4c-e), indicating that more solvents have evaporated. After sintering at a temperature in the range of $180-200{ }^{\circ} \mathrm{C}$ for 5 or 30 minutes, the average thickness of the silver film shows a stable $370-380 \mathrm{~nm}$.

Here, we also performed the printing experiment with an ink stored at $5{ }^{\circ} \mathrm{C}$ for more than 90 days to check its stability. The printing process is still smooth without any crystal precipitation or particle formation issues, further confirming the good stability of the ink. We also investigated the resistivity of the films from the ink stored at $5{ }^{\circ} \mathrm{C}$ for 90 days, which is about $15.72 \mu \Omega \mathrm{cm}$, a slight change, indicating the stability of the printed film.

\subsection{Printability of the optimal silver ink}

The printing of the optimal ink was conducted using a PixDro LP50 inkjet printer, using Spectra S-class printheads. The drop images of the ink at different times after the ejection from the printhead are given in Fig. 5a. After $60 \mu \mathrm{s}$, the drop is still connected with the nozzle via a filament. At a time of $80 \mu \mathrm{s}$, the drop detaches from the nozzle, and the filament flows into the main drop. After $120 \mu \mathrm{s}$, a spherical drop is obtained, which is free from a satellite drop or a filament, meaning good printability.

As expected, squares in $20 \mathrm{~mm} \times 20 \mathrm{~mm}$ were printed smoothly on glass substrates. Based on the results of Section 3.3, we chose $200{ }^{\circ} \mathrm{C}$ to sinter the square films printed with different resolutions in the range of $300 \mathrm{dpi}$ to $1050 \mathrm{dpi}$. SEM and four-probe analyses were used to investigate the effect of resolution on the film morphology, thickness and resistivity, see Fig. $5 \mathrm{~b}$ and Fig. S10 (in ESI $\dagger$ ). The films printed with $300 \mathrm{dpi}$ and $450 \mathrm{dpi}$ have a discontinuous morphology, where the number of silver particles is small and the interconnections between them are poor. The films printed using a resolution of 600 dpi and 750 dpi show good quality with uniform morphology. When higher resolution such as 900 or 1050 dpi was used, the morphology of the film is less uniform. The cross-section images of the printed square films show that the film thickness increases with the increase of the printing resolution, and there is a drastic increase when the resolution is $1050 \mathrm{dpi}$. The film achieved in 750 dpi shows the best quality and the lowest resistivity of $15.28 \mu \Omega \mathrm{cm}$. As for the reason, it is associated with the particle numbers generated in the film and the amount of the organic residues. The higher the resolution, the more ink dots per inch that the printer deposits. Therefore, to the squares with the same size, a higher resolution will bring more organic residues in the films and the silver ions cannot be transformed to silver in full amount under the same sintering time, resulting in a high resistivity. However, there is an optimal value, where the numbers of particles are just right which can produce a continuous film 
(a)
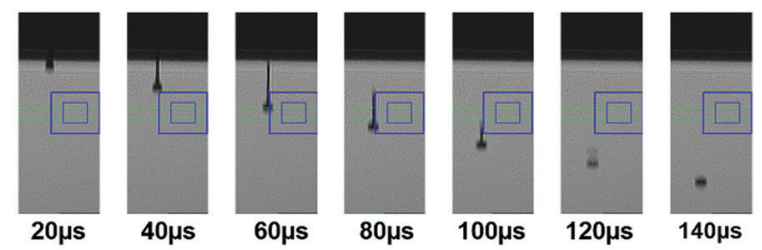

(b)

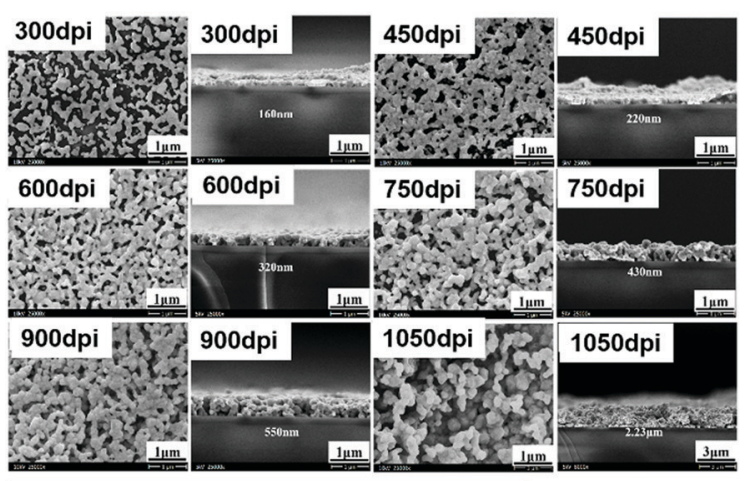

(c)

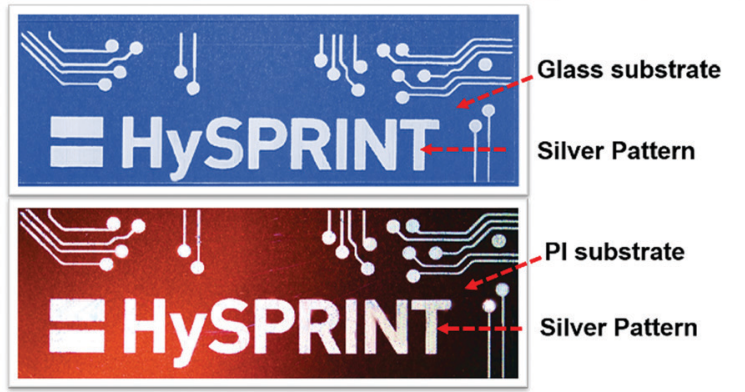

Fig. 5 (a) Drop images of the silver ink taken at different time after the ejection from piezo-head, (b) surface morphologies and cross-section images of the silver films printed with different resolution and sintered at $200^{\circ} \mathrm{C}$ for 60 minutes (on glass), (c) printed silver patterns on glass and $\mathrm{PI}$ substrates sintered at $200{ }^{\circ} \mathrm{C}$ for 60 minutes.

structure with a uniform thickness and few organic residues. In our case, it is at $750 \mathrm{dpi}$.

Olympus laser confocal microscope was used to analyze the surface roughness of the films printed with $750 \mathrm{dpi}$ and $900 \mathrm{dpi}$; the results are given in Fig. S11a and b (ESI $\dagger$ ). As the resolution increases, the roughness of the printed films increases from $0.142 \mu \mathrm{m}(\mathrm{Sq})$ to $0.165 \mu \mathrm{m}(\mathrm{Sq})$. This can be easily understood because more silver particles were generated, resulting in an increase in roughness. Fig. S11c (ESI $\dagger$ ) shows the images of the silver lines printed with different widths, where the smallest width is about $150 \mu \mathrm{m}$.

Fig. $5 \mathrm{c}$ shows some printed circuit patterns on glass and flexible PI substrates, indicating the good printability of our ink. The silver patterns on the PI substrate look rougher than it on the glass substrate.

The adhesion strength of the printed films on glass and PI substrates was assessed by a tape test according to the ASTM D3924 procedure, in which ASTM 5B and 0B represent the highest level of adhesion and the worst adhesion grade, respectively. The results are given in Fig. S12 (ESI $\dagger$ ). The film on the PI substrate exhibited an adhesion of grade $2 \mathrm{~B}$. An improved adhesion can be achieved by modifying the PI substrates with a solution of sodium hydroxide. ${ }^{59}$

\subsection{Cost and performance assessment}

Apart from the excellent electrical performance and favorable processability, cost is also a key factor to be considered for optimal inks, which should be as low as possible to serve low-cost printed electronics. We made a comparison of the developed silver particle-free inks in terms of type, cost (materials consumption), advantages and disadvantages respectively, see Table S1 in ESI. $\dagger$

As shown in Table S1 (ESI $\dagger$ ), the reported silver particle-free inks are not expensive and have a silver loading in the range of $10-25 \%$. A temperature around $150{ }^{\circ} \mathrm{C}$ is usually required to achieve a low resistivity in the order of $10^{-6} \Omega \mathrm{cm}$. These inks are compatible with most of the temperature-sensitive flexible substrates, which is a key advantage over nanoparticle silver inks. Even so, some of these inks are less stable and have sediment over time, while others decompose quickly and are not be suitable for a long-term inkjet printing process, despite these inks possessed the best conductivity. Besides, an ink with multiple ingredients could decrease the quality of the silver film due to the decomposition and evaporation of these components. Moreover, in most cases, the detailed printing information such as printing parameters, printing quality and the smallest line width are not provided. From Table S1 (ESI $\dagger$ ), it can be seen that our ink has a simple synthetic route, low cost, excellent printability and favorable conductivity. Further study will be focused on the conductivity and adhesion improvement on flexible substrates.

\section{Conclusions}

In summary, a stable, cheap and printable silver-particle free ink was formulated and characterized by using selected alcohols as the solvents. It was found that the alcohol type mainly affects the fluid properties of the ink, the morphology and electrical performance of the associated films. A mixture of solvents was a good choice, which not only provides the essential fluid properties for the inkjet printing but also results in highly conductive films with good quality. The obtained ink showed long-lasting stability without the occurrence of turbidity at lower temperatures $\left(5^{\circ} \mathrm{C}\right)$. It also exhibited compatibility with the inkjet printing technique. The printed $\mathrm{Ag}$ features yielded favorable conductivities $(15.46 \mu \Omega \mathrm{cm})$, about 10 times of bulk silver after annealing at $180{ }^{\circ} \mathrm{C}$. The research offers a low-cost, reliable and highly demanding material for flexible printed electronics, which can be made easily following a simple recipe.

\section{Conflicts of interest}

All authors declare that they have no conflict of interest.

\section{Acknowledgements}

The authors acknowledge the funding by the German Federal Ministry of Education and Research (BMBF), the Helmholtz Energy Materials Foundry (HEMF) and PEROSEED (ZT-0024) project. The authors are also grateful to Claudia Leistner, 
Carola Klimm, René Gunder and Michael Hengge for their assistance in the DSC-TG-MS, SEM, XRD and surface profile measurements respectively. This work was carried out in the framework of the Joint Lab GEN_FAB.

\section{References}

1 M. A. Leenen, V. Arning, H. Thiem, J. Steiger and R. Anselmann, Phys. Status Solidi A, 2009, 206, 588-597.

2 W. Li, Q. Sun, L. Li, J. Jiu, X.-Y. Liu, M. Kanehara, T. Minari and K. Suganuma, Appl. Mater. Today, 2020, 18, 100451.

3 Q. Huang and Y. Zhu, Adv. Mater. Technol., 2019, 4, 1800546.

4 W. Wu, Nanoscale, 2017, 9, 7342-7372.

5 A. Kosmala, R. Wright, Q. Zhang and P. Kirby, Mater. Chem. Phys., 2011, 129, 1075-1080.

6 K. R. Zope, D. Cormier and S. A. Williams, ACS Appl. Mater. Interfaces, 2018, 10, 3830-3837.

7 W. Yang, C. Wang and V. Arrighi, J. Electron. Mater., 2018, 47, 2824-2835.

8 M. Vaseem, G. McKerricher and A. Shamim, ACS Appl. Mater. Interfaces, 2016, 8, 177-186.

9 S. B. Walker and J. A. Lewis, J. Am. Chem. Soc., 2012, 134, 1419-1421.

10 T. Araki, T. Sugahara, J. Jiu, S. Nagao, M. Nogi, H. Koga, H. Uchida, K. Shinozaki and K. Suganuma, Langmuir, 2013, 29, 11192-11197.

11 D. Deng, T. Qi, Y. Cheng, Y. Jin and F. Xiao, J. Mater. Sci.: Mater. Electron., 2014, 25, 390-397.

12 Y. Dong, Z. Lin, X. Li, Q. Zhu, J.-G. Li and X. Sun, J. Mater. Chem. C, 2018, 6, 6406-6415.

13 Y. Farraj, M. Grouchko and S. Magdassi, Chem. Commun., 2015, 51, 1587-1590.

14 N. N. Jason, W. Shen and W. Cheng, ACS Appl. Mater. Interfaces, 2015, 7, 16760-16766.

15 D.-H. Shin, S. Woo, H. Yem, M. Cha, S. Cho, M. Kang, S. Jeong, Y. Kim, K. Kang and Y. Piao, ACS Appl. Mater. Interfaces, 2014, 6, 3312-3319.

16 F. Hermerschmidt, D. Burmeister, G. Ligorio, S. M. Pozov, R. Ward, S. A. Choulis and E. J. List-Kratochvil, Adv. Mater. Technol., 2018, 3, 1800146.

17 A. Al Shboul, C. Trudeau, S. Cloutier, M. Siaj and J. Claverie, Nanoscale, 2017, 9, 9893-9901.

18 C.-L. Lee, C.-H. Chen and C.-W. Chen, Chem. Eng. J., 2013, 230, 296-302.

19 D. Sinar, G. K. Knopf and S. Nikumb, Proc. SPIE, 2013, 8612, 861204.

20 T. S. Tran, N. K. Dutta and N. R. Choudhury, Adv. Colloid Interface Sci., 2018, 261, 41-61.

21 W. Yang and C. Wang, J. Mater. Chem. C, 2016, 4, 7193-7207.

22 S. H. Chae and Y. H. Lee, Nano Convergence, 2014, 1, 15.

23 J.-W. Han, B. Kim, J. Li and M. Meyyappan, Mater. Res. Bull., 2014, 50, 249-253.

24 N. Perinka, C. H. Kim, M. Kaplanova and Y. Bonnassieux, Phys. Procedia, 2013, 44, 120-129.

25 R. Brooke, D. Evans, M. Dienel, P. Hojati-Talemi, P. Murphy and M. Fabretto, J. Mater. Chem. C, 2013, 1, 3353-3358.
26 A. Chiolerio, S. Bocchini, F. Scaravaggi, S. Porro, D. Perrone, D. Beretta, M. Caironi and C. F. Pirri, Semicond. Sci. Technol, 2015, 30, 10.

27 C. N. Chen, C. P. Chen, T. Y. Dong, T. C. Chang, M. C. Chen, H. T. Chen and I. G. Chen, Acta Mater., 2012, 60, 5914-5924.

28 S. Magdassi, M. Grouchko, O. Berezin and A. Kamyshny, ACS Nano, 2010, 4, 1943-1948.

29 S. Jeong, H. C. Song, W. W. Lee, Y. Choi, S. S. Lee and B.-H. Ryu, J. Phys. Chem. C, 2010, 114, 22277-22283.

30 R. Shankar, L. Groven, A. Amert, K. W. Whites and J. J. Kellar, J. Mater. Chem. C, 2011, 21, 10871-10877.

31 D. J. Finn, M. Lotya and J. N. Coleman, ACS Appl. Mater. Interfaces, 2015, 7, 9254-9261.

32 H. Lu, J. Lin, N. Wu, S. Nie, Q. Luo, C.-Q. Ma and Z. Cui, Appl. Phys. Lett., 2015, 106, 093302.

33 Q. Huang, K. N. Al-Milaji and H. Zhao, ACS Appl. Nano Mater., 2018, 1, 4528-4536.

34 J. Liang, K. Tong and Q. Pei, Adv. Mater., 2016, 28, 5986-5996. 35 W. J. Scheideler, J. Smith, I. Deckman, S. Chung, A. C. Arias and V. Subramanian, J. Mater. Chem. C, 2016, 4, 3248-3255.

36 Q. Huang and Y. Zhu, Sci. Rep., 2018, 8, 1-10.

37 S. F. Jahn, T. Blaudeck, R. R. Baumann, A. Jakob, P. Ecorchard, T. Rüffer, H. Lang and P. Schmidt, Chem. Mater., 2010, 22, 3067-3071.

38 A. J. Kell, C. Paquet, O. Mozenson, I. Djavani-Tabrizi, B. Deore, X. Y. Liu, G. P. Lopinski, R. James, K. Hettak, J. Shaker, A. Momciu, J. Ferrigno, O. Ferrand, J. X. Hu, S. Lafreniere and P. R. L. Malenfant, ACS Appl. Mater. Interfaces, 2017, 9, 17227-17238.

39 X. Nie, H. Wang and J. Zou, Appl. Surf. Sci., 2012, 261, 554-560.

40 Y. Chang, D.-Y. Wang, Y.-L. Tai and Z.-G. Yang, J. Mater. Chem., 2012, 22, 25296-25301.

41 W. Yang, E. J. W. List-Kratochvil and C. Wang, J. Mater. Chem. C, 2019, 7, 15098-15117.

42 Y. Dong, X. D. Li, S. H. Liu, Q. Zhu, M. Zhang, J. G. Li and X. D. Sun, Thin Solid Films, 2016, 616, 635-642.

43 S. P. Chen, Z. K. Kao, J. L. Lin and Y. C. Liao, ACS Appl. Mater. Interfaces, 2012, 4, 7063-7067.

44 Y. Mou, Y. Zhang, H. Cheng, Y. Peng and M. Chen, Appl. Surf. Sci., 2018, 459, 249-256.

45 S. P. Chen, Z. K. Kao, J. L. Lin and Y. C. Liao, ACS Appl. Mater. Interfaces, 2012, 4, 7063-7067.

46 M. Vaseem, G. McKerricher and A. Shamim, ACS Appl. Mater. Interfaces, 2016, 8, 177-186.

47 C.-N. Chen, T.-Y. Dong, T.-C. Chang, M.-C. Chen, H.-L. Tsai and W.-S. Hwang, J. Mater. Chem. C, 2013, 1, 5161-5168.

48 K. Black, J. Singh, D. Mehta, S. Sung, C. J. Sutcliffe and P. R. Chalker, Sci. Rep., 2016, 6, 7.

49 K. S. Bhat, R. Ahmad, Y. Wang and Y. B. Hahn, J. Mater. Chem. C, 2016, 4, 8522-8527.

50 H. Hu and R. G. Larson, J. Phys. Chem. B, 2006, 110, 7090-7094. 51 W.-d. Yang, C.-y. Liu, Z.-y. Zhang, Y. Liu and S.-d. Nie, J. Mater. Chem., 2012, 22, 23012-23016.

52 R. D. Deegan, O. Bakajin, T. F. Dupont, G. Huber, S. R. Nagel and T. A. Witten, Nature, 1997, 389, 827-829. 
53 E. Tekin, B.-J. de Gans and U. S. Schubert, J. Mater. Chem., 2004, 14, 2627-2632.

54 F. Girard, M. Antoni and K. Sefiane, Langmuir, 2008, 24, 9207-9210.

55 P. J. Smith and D. H. Shin, Inkjet-based micromanufacturing, John Wiley \& Sons, 2012.
56 F. Mathies, E. J. List-Kratochvil and E. L. Unger, Energy Technol., 2020, 8, 1900991.

57 B. He, S. Yang, Z. Qin, B. Wen and C. Zhang, Sci. Rep., 2017, 7, 1-7. 58 D. Jang, D. Kim and J. Moon, Langmuir, 2009, 25, 2629-2635. 59 W.-d. Yang, C.-h. Wang, V. Arrighi, C.-y. Liu and D. Watson, J. Mater. Sci.: Mater. Electron., 2015, 26, 8973-8982. 